\section{EL ILUSIONISTA DE LAS PALABRAS: PAUL AUSTER Y SU UNIVERSO CREATIVO}

\author{
Esther Álvarez López \\ Universidad de Oviedo
}

\begin{abstract}
Paul Auster is one of the greatest writers of our time. Since 1994, to his work as novelist, poet and essayist he has added scriptwriting and film directing. Both literature and cinema appear closely linked in his creative production, so that one feeds the other and vice versa, by means of themes, common characters as well as self-referential and metafictional allusions. In novels, short stories and films, Auster reveals himself, in essence, as a great storyteller. They are stories that overlap at different narrative levels following the technique of the Chinese boxes. His work is also part of a large net of internal and external references in dialogue with each other, posing and pondering on questions that have to do with identity, writing or the intersections between fiction and reality, which appear recurrently both in its literary as in its filmic form.
\end{abstract}

KEY WORDS: Actor; Auster; author; bidimensional; Chinese boxes; external references; film; images; internal relations; intertextuality; myse-en-abyme; scripts; silent film; tridimensional; photograph; self-referential; storytellers; visual writing; writers.

Paul Benjamin Auster (Nueva Jersey, 1947) es sin duda el escritor contemporáneo estadounidense cuya trayectoria vincula más estrechamente la literatura y el cine. Al igual que otros grandes novelistas que le han precedido en el mundo de las letras de su pais, como William Faulkner (Premio Nobel de Literatura en 1949) o el llamado "portavoz de la generación perdida", Francis Scott Fitzgerald, el prolífico y versátil Auster abandona ocasionalmente el encierro en su habitación de escritor seducido por el irresistible magnetismo del cine, al que ha dedicado en los últimos años una gran parte de su energía creativa, tanto en calidad de guionista como de director.

A diferencia de algunos de sus colegas de antaño, sin embargo, no ha sido Hollywood la meca hacia la que ha dirigido sus pasos, atraído por el dinero fácil, el triunfo o la fama. Con mejor o peor fortuna ${ }^{1}$, Auster ha preferido invertir su esfuerzo en películas modestas de bajo presupuesto que, a cambio, le permitieran ejercer un mayor control sobre el complejo proceso cinematográfico sin tener que

\section{THE ILLUSIONIST OF WORDS: PAUL AUSTER AND HIS CREATIVE UNIVERSE}

RESUMEN: Paul Auster es uno de los grandes escritores de nuestro tiempo. Desde 1994, a su labor de novelista, poeta, traductor y ensayista ha añadido la de guionista y director de cine. Ambos medios, literatura y cine, aparecen estrechamente ligados en su producción creativa, de manera que uno nutre al otro y viceversa, a través de temas y personajes comunes, de guiños autorreferenciales y metaficcionales. En novelas, relatos y películas Auster se revela, en esencia, como un gran contador de historias. Se trata de historias múltiples que se superponen a distintos niveles narrativos siguiendo la técnica de cajas chinas. Su obra forma parte de una amplia red de referencias internas y externas que dialogan entre sí, al tiempo que plantean cuestiones en torno a la identidad, la escritura o las intersecciones entre ficción y realidad, que aparecen de manera recurrente tanto en forma literaria como fílmica.

PALABRAS CLAVE: Actor; Auster; autor; auto-referenciales; bidimensional; cajas chinas; cine; cine mudo; contadores de historias; escritores; escritura visual; fotografía; guiones; imágenes; intertextualidad; myse-en-abyme; referencias externas; relaciones internas; tridimensional.

"pervertir" su idea original por las exigencias o gustos del mercado. Al fin y al cabo, su éxito como escritor estaba ya bien consolidado con anterioridad a su primera incursión importante en el mundo del cine como guionista de Smoke ${ }^{2}$ (años antes, en 1993, había protagonizado un fugaz cameo en la película adaptación de su obra La música del azar, dirigida por Peter Haas) $)^{3}$. En Estados Unidos y en Europa la reputación de Paul Auster ha ido en aumento con cada sucesiva publicación, hasta llegar a ser uno de los novelistas más carismáticos, traducidos y leídos del panorama literario mundial.

Su original trabajo, tanto en el ámbito de la literatura como del cine, le ha hecho merecedor de múltiples premios y reconocimientos. De entre ellos, cabe destacar el Premio Príncipe de Asturias de las Letras en el año 2006, cuyo jurado valoró para la concesión del galardón "la renovación literaria que ha llevado a cabo al unir lo mejor de las tradiciones norteamericana y europea, innovar el relato cinematográfico e incorporar a la literatura algunas de sus 
aportaciones $^{\prime \prime}$. Sin embargo, puede que para el escritor nacido en Newark (Nueva Jersey) pero con alma de Brooklyn, donde reside, sea otro día, el 27 de febrero, el que atesore con mayor emoción: Marty Markowitz, presidente de ese condado de la ciudad de Nueva York, lo declaró oficialmente como Día de Paul Auster en 2005.

Su vocación de escritor nació a una edad muy temprana. En Why Write? cuenta cómo cuando tenía ocho años de edad y sólo le interesaba el baseball, deporte del que aún es gran aficionado, fue a ver jugar a su equipo favorito, los New York Giants. Al final del partido tuvo ocasión de pedirle un autógrafo a uno de los jugadores, Willie Mays. Sin embargo, ni el deportista, ni el niño, ni ninguna de las personas que lo acompañaban tenían con qué escribir, por lo que Mays se marchó sin estampar su preciada firma, dejando al pequeño Paul llorando de frustración y desconsuelo. A partir de esa noche comenzó a llevar un lápiz con él aunque no tuviera ningún plan concreto para usarlo. Según comenta, los años le enseñaron que si se lleva un lápiz en el bolsillo hay una gran probabilidad de que un día uno se sienta tentado a utilizarlo: "As I like to tell my children, that's how I became a writer" (Auster, 1996, 25).

Auster confiesa haber sido un "cinéfilo empedernido cuando era joven" (De Cortanze, 1999, 115), lo que puede explicar que a los diecinueve o veinte años ya escribiera un par de guiones. Resulta curioso comprobar que el autor, que siempre se mostró cautivado por las palabras, eligiera precisamente películas mudas para iniciarse en el mundo del cine (a las que regresa en El libro de las ilusiones con el personaje de Hector Mann). No obstante, cuando leemos su descripción de aquellos guiones sobre "comedias raras de caras imposibles y golpes", entendemos que, en realidad, estaban estrechamente vinculados a su interés por el lenguaje y la capacidad expresiva de éste: "Eran muy largos y muy detallados, setenta u ochenta páginas de complicados y meticulosos movimientos, cada gesto expresado en palabras" (Auster, 1995, 14). En definitiva, lo que Auster hacía a través de estos guiones de cine mudo era fundamentalmente practicar con el lenguaje, poner a prueba su plasticidad, su complejidad, las posibilidades que ofrecía para capturar los detalles más sutiles de la realidad y transmutarlos en algo vivo, una imagen, capaz de suscitar emociones. Estos primeros ensayos en el arte de lo que podemos denominar "escritura visual" fueron sin duda esenciales para ir perfilando ese carácter preciso a la vez que evocador e imaginativo de las palabras que Auster ha ido perfeccionando con cada sucesiva publicación.

A pesar de estos pasos iniciales en el mundo del séptimo arte y de su posterior trayectoria como guionista y director, Auster afirma tener ciertos problemas con el cine como medio. En su opinión, el cine, al contrario que una novela, es bidimensional, ya que consiste en la proyección de imágenes planas sobre una pared, imágenes que son sólo "un simulacro de realidad, no lo auténtico" (Auster, 1995, 14). Por el contrario, un libro crea mundos tridimensionales: "Hueles las cosas, las tocas, tienes pensamientos complejos e intuiciones". En el cine, por otro lado, tendemos a contemplar las imágenes de manera pasiva "y al final pasan a través de nosotros sin dejar huella", mientras que para leer un libro "tienes que implicarte activamente en lo que dicen las palabras. Tienes que trabajar, tienes que usar la imaginación". De este modo, concluye, "yo siempre me pondré de parte de los libros" (Auster, 1995, 14-15). Sin embargo, el recorrido artístico de Auster indica que el mundo bidimensional del cine ha ido ganando terreno poco a poco y se ha acercado a esa tridimensionalidad de la narrativa que al autor tanto le fascina, hasta que ambos llegan a confluir e incluso, de algún modo, a fusionarse en su obra.

Su primer guión llevado al cine es uno de esos productos híbridos en los que Auster combina magistralmente ambos medios artísticos. Smoke, dirigida por Wayne Wang, surge de un relato que el escritor había publicado para la página especial de Navidad del New York Times, titulado "El cuento de Navidad de Auggie Wren" (1990). Wang se había entusiasmado tanto con el cuento que le pide al autor que escriba el guión para su película. Augustus Wren, que en el texto impreso en el periódico aparece como el encargado del estanco en la calle Court, donde el propio Auster compra los puritos Schimmelpennicks que le gusta fumar, se acaba convirtiendo en el personaje principal del filme, y el estanco en la Compañia Cigarrera de Brooklyn. Paul Benjamin ("metí mi propio nombre para contribuir a la confusión". Auster, 1995, 25) es el escritor-narratario que transforma en literatura la fascinante historia que le sucede a Auggie un día de Navidad.

"Le oí este cuento a Auggie Wren": así comienza el relato original de Auster, que en el filme se desarrolla, con las variantes oportunas propias del medio, en la escena 71 , la 
última y más larga de la película, siguiendo la técnica de cajas chinas tan frecuente en su obra: El cuento de Navidad es, en definitiva, un texto literario convertido en texto filmico, concebido como parte independiente $y$, por tanto, no vinculado directamente a la línea argumental que se desarrolla con anterioridad, e inserto como un flashback dentro de otro texto más amplio, la película de Wang. Para subrayar su carácter distintivo de historia dentro de otra historia, así como su dualidad como texto narrativo por un lado y fílmico por otro, en el rodaje se han empleado técnicas especificas que diferencian esta escena del resto del metraje. Entre ellas destacan la utilización del blanco y negro frente al color; la voz en off de Auggie mientras interpreta los hechos que le describe a Paul, en contraposición al diálogo directo del presente, además de otros recursos, como la repetición y la cámara lenta para grabar el momento del encuentro entre el estanquero y la abuela que protagoniza su historia:

Vemos que Auggie vacila durante un segundo. Mientras su voz cuenta la siguiente parte de la historia, le vemos cediendo, abriendo los brazos y abrazando a la ABUELA ETHEL. EI abrazo se repite luego a cámara algo más lenta; después otra vez a cámara lenta; luego una vez más, a cámara muy lenta; luego de nuevo a cámara tan lenta que parece una secuencia de fotos fijas (Auster, 1995, 156).

Estas indicaciones que Auster introduce en el guión llaman nuestra atención no sólo sobre distintos aspectos de la cinematografía en sí sino también sobre el interés del autor por explorar la capacidad del cine para "narrar" como lo hace la literatura. Por un lado, el texto resalta el componente básico de todo film: la foto fija, o fotograma, que a través del montaje se convierte en imágenes en movimiento. Por otro, al tratarse de imágenes casi detenidas en el tiempo, se exige al público espectador que observe con detalle y participe activamente en un momento crucial de la historia que se relata: aquél en el que tanto la abuela Ethel como Auggie dejan de lado el mundo de la realidad/verdad para tácita, pero conscientemente, entrar en un juego de ficción compartida que les permite vivir su peculiar historia de Navidad. De este modo, Auster subraya la bidimensionalidad del cine, el hecho de que la gente "piensa que las películas son 'reales', pero no lo son" (Auster, 1995, 14), y lo hace a través del evidente carácter construido de este texto fílmico. Al mismo tiempo, trata de romper la tendencia del público espectador de ver las imágenes pasivamente, lo que contribuye, en su opinión, a que pasen a través de nosotros sin dejar huella. Por medio de estos recursos, Auster intenta acercarlas al mundo tridimensional, de implicación imaginativa, que asocia con la literatura.

Auggie Wren, el personaje principal de Smoke, comparte estas claves a través de lo que él denomina "la obra de mi vida" (Auster, 1995, 56). Su proyecto consiste en más de cuatro mil fotografías tomadas todos los días del año a las ocho de la mañana, en cualquier condición meteorológica, en la esquina de la calle 3 con la Séptima Avenida. Una vez reveladas, las imágenes pasan a formar parte de álbumes, catorce en total, catalogados por años, desde 1977 a 1990. En la esquina superior de cada una de las fotos el estanquero ha añadido una pequeña etiqueta blanca en la que figura la fecha concreta a la que corresponden las imágenes. Cuando Paul Benjamin examina uno de los álbumes, comenta atónito: "Son todas iguales" (Auster, $1995,57)$, mientras lo ojea rápidamente sin entender nada de lo que ve. Sin embargo, para Auggie cada una de esas fotografías es diferente de todas las demás:

Tienes mañanas luminosas y mañanas sombrias. Tienes luz de verano y luz de otoño. Tienes días laborables y fines de semana. Tienes gente con abrigo y botas impermeables y gente con pantalones cortos y camiseta. A veces son las mismas personas, otras veces son diferentes. $Y$ a veces las personas diferentes se convierten en las mismas y las mismas desaparecen. La tierra da vueltas alrededor del sol y cada día la luz del sol da en la tierra en un ángulo diferente (Auster, 1995, 56-57).

Paul comprende que debe ir más despacio para apreciar la variedad de aquella aparente igualdad que a él le resulta indistinguible. Es entonces cuando reconoce en una de las imágenes a Ellen, su esposa fallecida. Conmovido, percibe ahora que cada instantánea es única porque encierra, precisamente, un instante de una vida, que Auggie captura y plasma "como si pudiera imaginar historias para ellos, como si pudiera penetrar en los invisibles dramas encerrados dentro de sus cuerpos", tal y como observa Paul Benjamin/Auster en "El cuento de Navidad de Auggie Wren" (Auster, 1995, 164). Finalmente, el personaje-escritor comprende que sólo hay que mirarlas con detenimiento una a una, prestar más atención a los detalles, a las variaciones en los ángulos y cambios de luz, o a las sutiles diferencias 
del entorno, para darse cuenta de su especificidad, pero también de lo que cada una representa en sí misma y en relación con las demás. Las imágenes, comenta Auster refiriéndose a las del séptimo arte, nos "cautivan, nos intrigan y nos deleitan durante dos horas, y luego salimos del cine y apenas podemos recordar lo que hemos visto" (Auster, $1995,14)$. Esta frase podría aplicarse a Paul cuando contempla las fotos de los álbumes de Auggie sin implicarse en lo que ve. Pero, como buen artista, Auggie le muestra a su amigo cómo ser un espectador activo y convertir esas imágenes/textos visuales, proyectadas en su caso no sobre una pantalla sino sobre papel, en historias inolvidables.

Paul Auster ha demostrado a lo largo de su trayectoria que su interés reside, precisamente y ante todo, en contar historias, de tal manera que sus novelas y guiones resultan ser, en esencia, ejercicios prácticos en ese arte. Debido a este interés, no resulta sorprendente que personajes escritores de diversa indole protagonicen una gran parte de su obra narrativa y fílmica: El ya mencionado Paul Benjamin en Smoke, Paul Aaron y Benjamin Sachs en Leviatán (1992), David Zimmer en El libro de las ilusiones (2002), Sydney Orr en La noche del oráculo (2003), Mr. Blank en Viajes por el Scriptorium (2006), Martin Frost en La vida interior de Martin Frost (2007) y August Brill en Un hombre en la oscuridad (2008) -su última novela publicada hasta la fecha-, por citar sólo algunos de los nombres más representativos. Todos los títulos mencionados tienen como común denominador el hecho de que tratan sobre un escritor y que la trama gira en torno a las historias imaginadas, vividas, contadas por él.

En lo que al cine se refiere, Auster ha expresado su atracción por aquellos directores que, como él mismo, "dan más importancia a las historias que a la técnica, que se toman su tiempo para permitir que sus personajes se desarrollen ante sus ojos, que existan como seres humanos completos" (Auster, 1995, 15). Posiblemente aqui resida la razón de ser de sus propias películas, en las que introduce una nueva, aunque similar variante narrativa con respecto a sus obras literarias: en la mayoría de las ocasiones, los personajes no son tanto escritores como simples contadores de historias, gentes que no tienen pretensiones literarias o profesionales, a quienes sólo les mueve el puro placer de relatar. Los protagonistas de Smoke y Blue in the Face resultan ser ejemplos memorables. Harvey Keitel, actor que da vida a Auggie Wren en ambas cintas, afirma que el elemento más profundo de Smoke, "es el hecho de contar historias", lo que convierte a este filme en "una gran historia sobre el arte de contar". Paul Auster, guionista, señala por su parte que "todo el mundo en la película cuenta historias", mientras que el director, Wayne Wang, dice de Keitel que es un gran narrador de historias: "Es mejor narrador que Paul, aunque Paul sea el escritor"5.

Un objetivo similar, si bien más experimental e innovador que el anterior, da lugar a Blue in the Face, dirigida también por Wang y con Auster como co-director. Considerada una continuación de Smoke, comparte algunos personajes y escenarios aunque miran en direcciones diferentes. Si la base de la primera de ellas es el arte de contar historias, "el motor" de esta segunda incursión de Paul Auster en el mundo del cine "son las palabras" (Auster, 1995, 173). Rodada en dos períodos de tres días, son los propios actores, sin guión previo y sólo con unas notas escritas por el autor como preparación de los personajes que cada uno ha de interpretar, quienes van creando de forma improvisada las situaciones de las diferentes escenas. El resultado es una polifonía de voces autoriales que crean, en colaboración y de manera colectiva, un interesante collage de historias sobre la vida cotidiana en Brooklyn.

Auster es un firme convencido de que las historias son parte esencial de la vida de todo ser humano, tanto como lo es la escritura para sí mismo. La importancia que otorga tanto a las primeras como a la segunda queda puesta de manifiesto en las opiniones que vierte en las numerosas entrevistas de que es objeto y que, reiteradas casi palabra por palabra en distintos medios, son nuevamente eje del discurso que pronuncia en el acto de entrega de los Premios Príncipe de Asturias en octubre de 2006. En él vuelve una vez más a centrar su atención en la escritura como arte y como profesión, en su utilidad o pretendida falta de ella ("¿qué tiene de malo la inutilidad", se pregunta, cuando "el valor del arte reside en su misma inutilidad?")6, al tiempo que se refiere más detalladamente a la fundamental necesidad e impulso humanos de crear e inventar historias: "En cuanto aprendemos a hablar, comenzamos a sentir avidez por los relatos" - señala en su intervención. Es éste, sin embargo, un deseo que va más allá de la infancia porque se trata de una necesidad universal. El autor afirma que a pesar de que las cifras sobre lectura de libros parecen descender año a año, este hecho no ha disminuido en absoluto el interés del público por los relatos. Bien sea en 
forma de novelas, cine, televisión o incluso de tebeos, todo relato es alimento que sirve para satisfacer el hambre de historias imaginarias común al ser humano. Son ellas, por otro lado, las que nos permiten experimentar un encuentro con nuestros miedos y tormentos en un entorno perfectamente seguro y protegido: "Tal es la magia de los relatos", concluye, "pueden transportarnos a las profundidades del infierno, pero en realidad son inofensivos".

El escritor/director está convencido de que las historias nos ayudan a organizar la realidad y a encontrarle un sentido a las cosas: "It's through stories that we struggle to make sense of the world" (Auster, 1997, 336). De ahi que regrese una y otra vez a sus preocupaciones más profundas, a sus temores inconscientes, a través de la similitud de tramas y la reaparición de personajes. Consigue tejer así una extensa tela de araña con la que envuelve sus textos, de tal manera que podemos afirmar con él que "siempre se acaba escribiendo el mismo libro; cada libro constituye una especie de réplica del anterior" (De Cortanze, 1999, 81). La intertextualidad y los guiños autorreferenciales se convierten, así, en una marca distintiva de su creación artística, en la que elementos diversos del mundo de la ficción, textos y personajes establecen vínculos no sólo entre las distintas novelas, sino también entre novelas y películas, películas y relatos, configurando de esta forma esa sutil red de relaciones internas que resulta ser tan del gusto del público austeriano.

A todo ello se añaden numerosas referencias externas, implícitas y explícitas, con las que construye un sugerente universo de ficción en el que los textos dialogan entre sí y a través del cual plantea, sin aparentemente responder, las cuestiones existenciales que le han marcado como persona, como escritor y director: la identidad, las relaciones del yo con los otros, la muerte, la contingencia, la intersección entre ficción y realidad, etc. Este mundo de interrelaciones, unido a la recurrencia de la técnica de cajas chinas, o myse-en-abyme, complica aún más sus obras al tiempo que las enriquece. En conjunto, este juego activo de referencias estimula, tanto desde un punto de vista intelectual como imaginativo, a quienes se adentran en las profundidades narrativas de este polifacético creador.

Un ejemplo revelador de este complejo entramado de conexiones lo encontramos en la última película dirigida por Paul Auster hasta la fecha: La vida interior de Martin Frost.
El título nos remite directamente a El libro de las ilusiones, donde se incluye como una de las catorce películas realizadas por el actor-convertido-en-director Hector Mann, destinadas por su expreso deseo a no ser nunca mostradas al público, en lo que sin duda es un acto de nihilismo extremo. Es, además, la única que el protagonista, David Zimmer, ha podido visionar, así como narrar en forma de libro antes de su destrucción. De esta manera, será este libro que Zimmer escribe sobre Mann, y no sus películas, el que hará que el director sobreviva tras su muerte. Algunos críticos han considerado esta novela sobre escritores y cineastas "una declaración del poder de la palabra sobre la imagen" (Brown, 2007, 126) y, atendiendo al contenido de la película que Zimmer ve en el rancho de Mann en Nuevo México, podemos interpretarla igualmente como una exploración tanto del poder de las historias como del acto mismo de contarlas.

David Zimmer hace aquí su tercera incursión narrativa, puesto que, como es característico ya en Auster, el personaje había aparecido en dos de sus novelas anteriores. Antes de la muerte de su mujer e hijo en un trágico accidente, que le hace retirarse prematuramente de su profesión como profesor de universidad, el trabajo académico de Zimmer le había llevado a explorar los libros, el lenguaje y la palabra escrita. Tras conocer la obra del actor-cineasta Hector Mann, se convierte en un experto en cine mudo y en el cine como lenguaje visual. Tras varios años de dedicación, ha logrado asimismo completar la traducción de los dos volúmenes de dos mil páginas de las memorias de Chateaubriand, tituladas Memorias de un hombre muerto. Como sorpresa final, los lectores son informados de que las páginas que están leyendo son las memorias del propio $\mathrm{Zi}$ mmer, presentadas, al igual que las del escritor francés, de manera póstuma (al final del libro el personaje informa a sus lectores de que habla desde la tumba). De esta manera, la obra de Chateaubriand revela la mecánica de la obra del escritor Auster a través de la obra de su narrador Zimmer, una técnica que llama la atención sobre las convenciones de la propia escritura (Brown, 2007, 126).

La idea para La vida interior de Martin Frost, de la que habíamos partido antes de dejarnos atrapar por la enredosa telaraña de relaciones que recorre la obra de Auster, le había surgido al escritor con anterioridad a que fuera incorporada como parte de su novela. El texto inserto finalmente en ella es una versión abreviada, escrita en

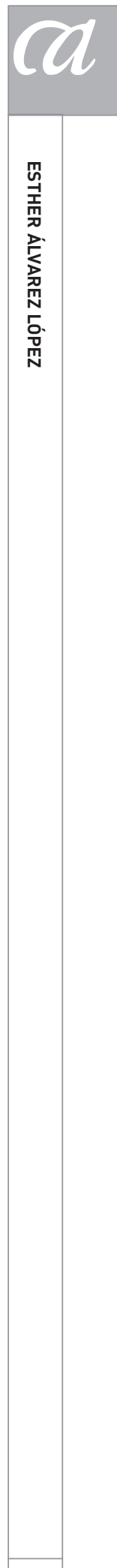


clave narrativa, de un corto previo de unos 30 minutos que una productora alemana le había solicitado; formaría parte de una serie compuesta por las aportaciones de doce directores sobre el tema de hombres y mujeres que llevaria por título Erotic Tales. A causa de determinadas cláusulas contractuales que le suscitan dudas, Auster finalmente se retira del proyecto (Auster, 2007, 1-2). A pesar de que, como hemos mencionado, El libro de las ilusiones Ilama la atención sobre la cualidad potencialmente efímera del cine en comparación con la novela, y parece alzarse en testimonio de la primacía de esta forma, el director regresa una vez más al mundo de la cinematografía para realizar la película que lleva como título el mismo de la obra de Mann, la cual trata, eso sí, sobre el poder performativo de las palabras.

Siguiendo con las relaciones internas entre unas obras y otras, así como entre éstas y referencias externas, leemos que Viajes en el Scriptorium, una de las últimas novelas publicadas por Auster, resulta ser igualmente el título de otra de las películas de Hector Mann en El libro de las ilusiones. Se trata, además, de la segunda novela del escritor-personaje Martin Frost, cuya fantástica historia en el filme que lleva su nombre se inspira a su vez en la obra de Nathaniel Hawthorne (en concreto de "The Birthmark", un relato de 1837), uno de los escritores norteamericanos preferidos de Auster, con quien ha sido comparado (Barone, $1995,1)$ y a quien le debe no pocas influencias?

En esta misma línea de confluencias filmicas y literarias se halla Lulu on the Bridge (1998), cuyo germen se desarrolló originalmente en forma de guión cinematográfico. Más tarde, Auster trató de convertirla en novela, pensando que "si la idea era buena, no importaba cómo la contara. Libro, cine..., era indiferente. La sustancia del relato sería su propio combustible, con independencia de la forma que adoptara" (Auster, 1998, 157). Sin embargo, el cambio no parecía encajar, pues era "una historia predominantemente dramática, no narrativa, y necesitaba ser vista, no tan sólo leída" (Auster, 1998, 158), por lo que, tal y como la estaba escribiendo, resultaba ser un completo fracaso. Fue así cómo Lulu regresó al formato con el que había nacido, si bien retuvo el argumento novelesco, que funciona a la vez a varios niveles diferentes: onírico, real, metafórico y mágico.

En el filme se hacen constantes alusiones literarias, filmicas y fotográficas a Pandora, mito que, como muchos otros antes que él, el autor/director revisita para desarrollarlo en una película integrada dentro de su propia película, cuyo rodaje es parte de la trama y también de la imaginación, en forma onírica, del moribundo Izzy Maurer, en un nuevo ejemplo de myse-en-abyme. Esta producción secundaria pretende, en palabras del director, ser una adaptación, modernizando los detalles, de la cinta protagonizada por Louise Brooks Die Büsche der Pandora [La caja de Pandora (Lulú), 1928], dirigida por Georg Wilhelm Pabst, en la que Brooks da vida al personaje de Lulu. El director alemán se nutrió, a su vez, de las piezas teatrales El espiritu de la tierra y La caja de Pandora, firmadas por Frank Wedekind, que Auster también utilizó como referencia para la realización de su largometraje.

La obra filmica y narrativa de Paul Auster es una constante reflexión sobre sí misma; también indaga, de manera casi obsesiva, sobre la escritura, sobre la relación del escritor/ director con sus propias creaciones de ficción y con las obras literarias y filmicas de otros escritores/directores, sobre cómo el mundo de la imaginación se entrecruza con la realidad o cómo lo ficticio y lo real se llegan a intercambiar. Juega, por otro lado, con nuestras propias expectativas como lectores/espectadores, ya que nos hace partícipes de la confusión que borra los límites entre ficción y realidad poniendo ante nosotros los mecanismos del proceso narrativo (literario o filmico) y revelando nuestro papel en el mismo. Nos encontramos a menudo con recursos que subrayan ambos aspectos: la ya mencionada interacción del ámbito real y el ficticio así como la propia naturaleza del acto de escribir, que han llegado a convertirse en caracteristicas distintivas, casi en marcas personales de su obra. Uno de tales recursos es el uso de homónimos del autor en el elenco de personajes que pueblan su mundo de ficción: Un tal Paul Auster aparece por primera vez dentro de la narración, y no sólo en la portada del libro, en La ciudad de cristal, la novela que inicia la Trilogía de Nueva York y se presenta de manera recurrente por medio de distintas variaciones nominales en otras de sus obras. En Smoke, como hemos visto, el escritor Paul Benjamin, nombre con el que Auster firmó una de sus primeras obras, Jugada de Presión (1982), es uno de los personajes centrales.

En "¿Qué es un autor?", el pensador Michel Foucault ${ }^{8}$ se refiere a la "función autor" como un constructo lingüistico, puesto que se trata del nombre dado a una posición de sujeto dentro del lenguaje (al igual que "lector") o, más 
específicamente, de un texto. De este modo, el "autor" es deconstruido, se muestra sólo como parte de una estructura, existe en tanto que producto de un texto o de la escritura. El "nombre del autor" cumple asimismo, en opinión del filósofo francés, una función dentro de las relaciones socio-literarias. Es, en primer lugar, un nombre propio, un significante que designa un individuo específico e histórico (designación), a cuya biografía e incluso fotografía solemos tener acceso a través de la sobrecubierta del libro. Al mismo tiempo, tal nombre alude a la forma de pensar, la metodología y/o los escritos o formas de discurso asociados con él (descripción). Por tanto, el nombre propio como significante puede referirse tanto al significado de la persona concreta como al de la obra/ideas. En ambos casos, la relación entre significante y significado -entre el nombre propio y lo que designa o describe-es arbitrario y separable.

A la luz de esta teoría de Foucault, podemos afirmar que Paul Auster se deconstruye conscientemente como autor en su obra, y lo hace en su caso por un deseo de implicarse en la maquinaria del libro, tal como ha apuntado al hablar del personaje-"autor" de su mismo nombre en Ciudad de cristal. La presencia de estos otros "Paul Auster" en sus obras, o en su otra variante con las iniciales P.A., no nos conduce a pensar, sin embargo, en un yo autobiográfico (más allá de indicarnos, tal vez, que los escritores se nutren de sus propias experiencias o de personas reales para crear personajes), sino que llama la atención sobre la "persona" de la "función autor", utilizando los términos foucaultianos. El propio Auster denomina esta posición como "my author self", que define como "that mysterious other who lives inside me and puts my name on the covers of the books". Su intención al trasladar el nombre de la portada al interior del relato es abrir el proceso de escritura, "to break down the walls, to expose the plumbing" (Auster, 1997, 308).

Según confiesa, se siente fascinado por esa especie de extraño truco por el cual, aunque el nombre figure en la cubierta, una vez que se abre el libro el autor desaparece, de tal manera que es como si nadie en realidad hubiera escrito las palabras que se están leyendo. Ésa es la idea con la que concluye y que nos hace pensar en el hecho de que el "autor" es tanto una ilusión como una realidad o, en sus propias palabras, "The self that exists in the world -the self whose name appears on the covers of books-is finally not the same self who writes the book" (Auster,
1997, 308). En definitiva, este intercambio entre lo real y lo ficticio demuestra, una vez más, la naturaleza lingüística de la identidad. Esta idea de la dualidad del autor, que es a un tiempo el mismo y otro, ha perseguido a Auster desde los inicios de su carrera como escritor.

En La invención de la soledad introduce una frase de Rimbaud, "Je est un autre" ("Yo es otro"), que resume en esencia su concepto sobre la identidad autorial: "In the process of writing or thinking about yourself, you actually become someone else" (Auster, 1997, 277). Incluso ha llegado a comparar su labor de autor al escribir una novela con la de actor, de nuevo estableciendo estrechas conexiones entre literatura y cine. Estas dos palabras, autor/actor, no sólo son similares en su significante sino que comparten una idea semejante del hacer de los seres a quienes designan, en el sentido de que ambos, autor y actor, han de meterse en la piel de otro personaje, de otro ser imaginario, con el fin de darle cuerpo y verosimilitud, de conferirle un peso y una realidad. La transmutación del yo real en el otro ficticio es tal que, en palabras de Auster, "acabas por convertirte en ese otro personaje, en ese otro ser imaginario" (De Cortanze, 1999, 90).

No oculta el escritor/director este persistente interés de explorar (y explotar) las intersecciones entre ficción y realidad a través de la "persona" autor/actor, teniendo a la escritura como nexo de unión. En su trabajo cinematográfico más reciente, La vida interior de Martin Frost, vuelve a "romper la pared" para ofrecer al público espectador avezado un ejemplo más de intromisión autorial. En este filme, la casa-escenario donde discurre la acción pertenece en la ficción a Jack y Diane Restau, apellido que reorganizado convenientemente se convierte, una vez más, en "Auster". Por otro lado, las fotos familiares, y reales, del escritor (con su esposa, Siri Hustvedt, y su hija Sophie) son parte del decorado y, por lo tanto de la ficción, de la película; finalmente, su inconfundible voz da vida al narrador dentro de la diégesis filmica: "Everyone who sees the film will know from the credits I'm the writer and director. I'm the man who wrote the story about the man who wrote the story about the man who wrote the story. Why pretend otherwise?" (Auster, 2007, 19).

Este comentario bien nos puede servir como conclusión del presente estudio, pues en el texto se dan cita algunas de las características que hemos destacado sobre su obra a lo 
largo de estas páginas: su labor como escritor y director, sin que podamos establecer claramente los límites de uno y otro; las intersecciones entre ficción y realidad; la técnica de cajas chinas, etc. Sus palabras finales dejan entrever la que, en mi opinión, es su verdadera identidad, pues este ilusionista de las palabras no es tan sólo un escritor o un director, ni siquiera ambas cosas a la vez. Por encima de etiquetas clasificadoras, Paul Auster es ante todo un gran contador de historias, uno de los más grandes de nuestro tiempo.

\section{NOTAS}

1 Aunque Smoke fue galardonada con varios premios en distintos festivales europeos, Lulu on the Bridge no obtuvo el mismo favor de crítica y público, lo que llevó a su abandono por parte de los distribuidores. La vida interior de Martin Frost tampoco parece haber conseguido un reconocimiento generalizado.

2 Smoke (1994). Dir. Wayne Wang.

3 La música del azar (1993). Dir. Peter Haas.

4 Fundación Príncipe de Asturias. http://www.fundacionprincipedeasturias.org/esp/04/premiados/discursos/discursoig818.html. Consultada el 23 de junio de 2008.

5 Smoke. Entrevistas con el director, guionista, actor principal en el DVD.

6 Fundación Príncipe de Asturias. http://www.fundacion principedeasturias.org/esp/04/premiados/discursos/discursoig818.html. Consultada el 23 de junio de 2008.

7 En julio de 2002 escribe una larga introducción a la obra de Hawthorne Twenty Days with Julian \& Little Bunny by Papa (New York: New York Review of Books, 2003): vii-xliv.

Recibido: 20 de febrero de 2009

Aceptado: 23 de abril de 2009 http://www.henciclopedia.org.uy/autores/Foucault/Autor.html.
9 Michel Foucault. "¿Qué es un autor"?

\section{BIBLIOGRAFÍA}

Auster, Paul (1996): "Why Write?", en Why Write?, Providence, Burning Deck, 11-25.

- (1993): Leviatán, trad. Maribel de Juan, Barcelona, Anagrama.

- (1994): La invención de la soledad, trad. M. ${ }^{a}$ Eugenia Ciocchini, Barcelona, Anagrama (col. Compactos).

- (1995): Smoke \& Blue in the Face, trad. Maribel de Juan, 3. ${ }^{a}$ ed., 2006, Barcelona, Anagrama.

- (1996): La trilogía de Nueva York, trad. Maribel de Juan, Barcelona, Anagrama.

- (1997): The Art of Hunger. Essays, Prefaces, Interviews and The Red Notebook. Expanded Edition, Harmmondsword, Middlesex, Penguin.

- (1998): Lulu on the Bridge, trad. Javier Calzada, Barcelona, Anagrama.

- (2003): El libro de las ilusiones, BarceIona, Anagrama.

- (2006): Travels in the Scriptorium, Londres, faber and faber.

- (2007): The Inner Life of Martin Frost. A Film by Paul Auster, Nueva York, Henry Holt (Picador).

- (2008): Man in the Dark, Nueva York, Henry Holt.

Barone, Dennis, ed. (1995): Beyond the Red Notebook. Essays on Paul Auster, Philadelphia, University of Pennsylvania Press.

Brown, Mark (2007): Paul Auster. Contemporary American and Canadian 
Novelists, Manchester, Manchester University Press.

Cortanze, Gérard de (1999): Dossier Paul Auster. Prólogo de Rafael Conte, Barcelona, Anagrama.

Foucault, Michel (1969): “¿Qué es un autor?" http://www.henciclopedia.org.
uy/autores/Foucault/Autor.html. Consultada el 25 de junio de 2008.

\section{FILMOGRAFÍA}

Blue in the Face (Dirs. Paul Auster y Wayne Wang, 1995).
La vida interior de Martin Frost (The Inner Life of Martin Frost, Dir. Paul Auster, 2007).

La música del azar (The Music of Chance, Dir. Peter Haas, 1993).

Lulu on the Bridge (Dir. Paul Auster, 1998). Smoke (Dir. Wayne Wang, 1994). 